\title{
Tailoring of composite cantilever beam for maximum stiffness and minimum weight
}

\author{
P.Satheesh Kumar Reddy ${ }^{1}$, Kancharla Bhargavi ${ }^{2}$, Ch.Nagaraju ${ }^{3}$ \\ ${ }^{1,2,3}$ (Mechanical Engineering, V. R. Siddhartha College Of Engineering, INDIA)
}

\begin{abstract}
As the natural resources goes on decreasing now a days and to meet the needs of natural resources conservation, energy economy most of the manufacturers and their sub contractors are attempting to reduce the weight of the members in recent years. In this approach they are searching for low cost, high strength to weight ratio materials. Substituting composite structures for conventional metallic structures has many advantages because of higher specific stiffness and strength of composite materials. Composite materials have the major advantage of high strength to weight ratio with continuously decreasing travel of cost in addition to other advantages like excellent corrosive resistance, superior torsional buckling and fatigue strength and high specific strain energy storage capacity. The present work aims at the suitability of composite materials usage, by the identification of optimal fiber orientation stacking sequence and tailoring for laminate thickness/width for maximum stiffness and minimum weight design of laminated composite beam. The structural response is evaluated from conventional metallic structure with optimization techniques for maximizing stiffness and minimum weight. These metallic optimum values are extended initially to composite beam to maintain strength with the developed of optimization algorithm. Later with topology optimization and by tailoring cross-sections algorithm of the beam is evaluated with optimal fiber orientations and stacking sequence to maintain strength as in additional advantage of less weight for composites. Tailoring is done based on gradual decrement in cross-section over the length in both thickness and width direction. Numerical results are presented for cantilever beam with different geometries showing the maximizing stiffness and with minimum weight. The results indicate that the devised strategy is well suited for finding optimal fiber orientations and laminate thickness/width in the tailoring design of slender laminated composite structure.
\end{abstract}

Keywords: Fiber Orientation, Stacking Sequence, Tailoring, Topology

\section{Introduction}

Fiber reinforced composite materials have gained a widespread popularity over conventional materials in fields such as aerospace, construction, consumer products, transportation and sporting goods. For structural applications where high strength-to-weight and stiffness-to-weight ratios are required the fiber-reinforced composite materials are ideal. By altering lay-up and fiber orientations composite material can be tailored to meet the particular requirements of stiffness and strength. The ability to manufacture a composite material as per its job is one of the most significant advantages of composite material over an ordinary material. Due to the high strength to low weight ratio, resistance in fatigue and low damping factor, composite materials have wide range of applications in car and aircraft industries. Research in the design of mechanical, aerospace and civil structure and development of composite materials has grown tremendously in few decades. The problem of selecting a suitable material has been studied for a long time. One of its applications concerns the selection of the optimal distribution of fiber orientations in composite structures [1-3] and the identification of the optimal stacking sequence [4-8]. In most aerospace applications, the candidate materials are restricted to the conventional angles with plies oriented at $0^{\circ}, 45^{\circ},-45^{\circ}$ and $90^{\circ}$. This is by nature a discrete optimization problem. However, the specific parameterizations discussed here allow working with a continuous formulation, and reliable optimization methods developed for problems involving continuous variables can therefore be applied.

\section{Literature Survey:}

The objective is herein to establish a methodology for the identification of optimal fiber orientations in maximum stiffness and minimum weight design of laminated composite beams. The static structural response of the composite beam is evaluated using a beam finite element model capable of correctly predicting the effect of the fiber orientations. The aim is to set the foundations for future research which will extend the application to structural design of wind turbine blades with aero-elastic constraints. Several approaches for optimization of laminate lay-ups have been reported in the literature. Some of these are based on the assumption that the design variables should only take discrete values. Algorithms used for these type of problems include genetic algorithms (Le Riche and Haftka 1993; Gürdal et al. 1999), particle swarm methods (Kathiravan and Ganguli 2007) and branch-and-bound methods (Stolpe and Stegmann 2007). Other approaches consider continuous design variables. In this case, it is often possible to compute the gradients (sensitivities) of the objective function 
and constraints. It is then possible to state nonlinear optimization problems which can be solved using robust and efficient numerical gradient-based optimization methods. The main advantage of these type of methods is that in general a relatively small number of objective and constraint function evaluations is required. This is a critical aspect when dealing with large, computationally expensive analysis models like nonlinear aero-elastic models of wind turbine blades.

Different parameterizations have been put forward in this context. Pedersen (1991) presented an approach based on the minimization of the elastic strain energy in the optimal thickness and fiber orientations design of structures subjected to in-plane loads. Tsai and Pagano (1968) introduced the concept of lamination parameters or laminate invariants which allow for the definition of a convex design space in maximum stiffness design problems. Later, Miki and Sugiyama (1993) and Hammer et al. (1997) employed lamination parameters in the design optimization of laminated composite structures. Another approach inspired by the ideas of multiphase topology optimization has been presented by Lund and Stegmann (2005) and Stegmann and Lund (2005). The so-called discrete material optimization approach uses a material interpolation model to force the continuous variables to approach discrete values.

\section{Recognization Of Need:}

- As the natural resources goes on decreasing now a days and to meet the needs of natural resources conservation, energy economy most of the automobile manufacturers and their sub contractors are attempting to reduce the weight of the vehicles in recent years.[7]

- Automobile with high strength contains more weight which leads to high specific fuel consumption.

- Examples: Ambassador, Innova etc.,

- Automobile with less weight contains low strength which leads complete damage during collisions or accidents.

- Examples: Nano car, Maruthi 800, Also etc.,

\section{Solution:}

- Automobile with high strength to weight ratio leads to low specific fuel consumption and less damage to vehicles during collisions and also meets the needs of natural resource conservation.

- Automobile Manufacturers and their sub-contractors are searching for alternate materials which are having low cost, High strength to Weight Ratio.

- Substituting composite structures for conventional metallic structures in automobile industries has many advantages because of higher specific stiffness and strength of composite materials.

The objective of this paper is

\section{Objective:}

- To search for the specifications of the existing conventional cantilever beam.

- Developing an optimization algorithm to optimize steel cantilever beam.

- Optimum dimensions are extended to composite cantilever beam.

- Tailoring the composite beam by thickness and width directions.

- Optimizing the tailored composite beam with fiber orientations and stacking sequence.

- Checking the performance of tailored and optimized composite beam with conventional/ optimized steel cantilever beam.

\section{Design For Optimum Steel Cantilever Beam}

A classical definition for optimum design is the one by Wilde (1978) "the best feasible design according to a preselected quantitative measure of effectiveness". In optimal structural design a certain objective function, (structure weight in many cases) must be minimized or maximized by modifying the design variables while satisfying a set of behaviour and design constraints. Thanks to the use of computers the final optimum design can be accomplished by mathematical methods. This efficient and logical approach contrasts with the use of heuristic rules which characterizes the conventional design process. Several examples of structural optimization can be found in the literature (McGhee et al. 1991; Cohn and Lounis 1993; Arora 1997; Burns 2002; Negrao and Simoes 2004).

Table 1: Material Properties of High-strength-lowalloy structural steel(ASTM-A913 Grade 450)

\begin{tabular}{|c|l|c|c|c|}
\hline Sl. No & Properties & Notation & Unit & Value \\
\hline 1 & Modulus of Elasticity & $\mathrm{E}$ & $\mathrm{GPa}$ & 200 \\
\hline 2 & Yield Strength & $\sigma_{\mathrm{y}}$ & $\mathrm{MPa}$ & 550 \\
\hline 3 & Ultimate tensile strength & $\mathrm{UTS}$ & $\mathrm{MPa}$ & 450 \\
\hline 4 & Density & $\rho$ & $\mathrm{Kg} / \mathrm{m}^{3}$ & 7860 \\
\hline
\end{tabular}


Tailoring of composite cantilever beam for maximum stiffness and minimum weight

Table2: Design Requirement and specifications

\begin{tabular}{|c|l|c|c|c|}
\hline Sl. No & Specification & Symbol & Units & Value \\
\hline 1 & Bending Stress & $\sigma_{\mathrm{b}}$ & $\mathrm{MPa}$ & 250 \\
\hline 2 & Deflection & $\delta$ & $\mathrm{mm}$ & 5 \\
\hline 3 & Length & $\mathrm{L}$ & $\mathrm{mm}$ & $100-500$ \\
\hline 4 & Breath & $\mathrm{B}$ & $\mathrm{mm}$ & $10-50$ \\
\hline 5 & Thickness & $\mathrm{t}$ & $\mathrm{mm}$ & $10-25$ \\
\hline
\end{tabular}

\section{Optimization Parameters:}

- Objective function: Minimize Weight

Weight $=$ Length $\mathrm{x}$ breath $\mathrm{x}$ thickness $\mathrm{x}$ density

- Design Constraints: Stress \& Deflection

Bending stress $=\mathrm{M} \mathrm{x} \mathrm{y} / \mathrm{I}<250 \mathrm{MPa}$

Deflection $=\mathrm{W} \mathrm{L}^{3} / \mathrm{E} \mathrm{I}<5 \mathrm{~mm}$

- Design variables : Length, breath, thickness

$100 \mathrm{~mm}<$ Length $<500 \mathrm{~mm}$

$10 \mathrm{~mm}<$ Breath $<50 \mathrm{~mm}$

$10 \mathrm{~mm}<$ Thickness $<25 \mathrm{~mm}$

\section{Permutation And Combination Optimization Procedure:}

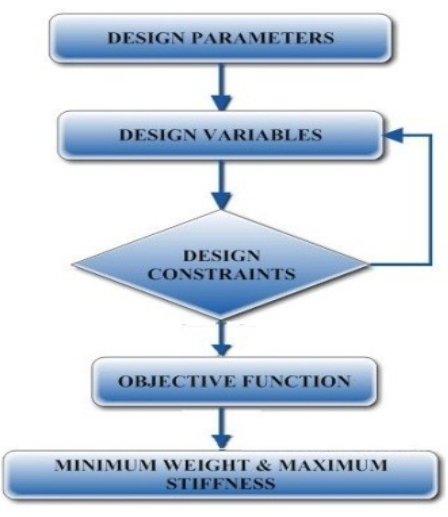

Table 3: Optimum results over conventional results

\begin{tabular}{|l|c|c|c|}
\hline Specification & Conventional & Optimized & Units \\
\hline Weight & 4.9 & 0.79 & $\mathrm{Kg}$ \\
\hline Bending Stress & 108 & 260 & $\mathrm{MPa}$ \\
\hline Deflection & 3.2 & 3.2 & $\mathrm{~mm}$ \\
\hline Length & 500 & 200 & $\mathrm{~mm}$ \\
\hline Breath & 50 & 50 & $\mathrm{~mm}$ \\
\hline Thickness & 10 & 10 & $\mathrm{~mm}$ \\
\hline
\end{tabular}

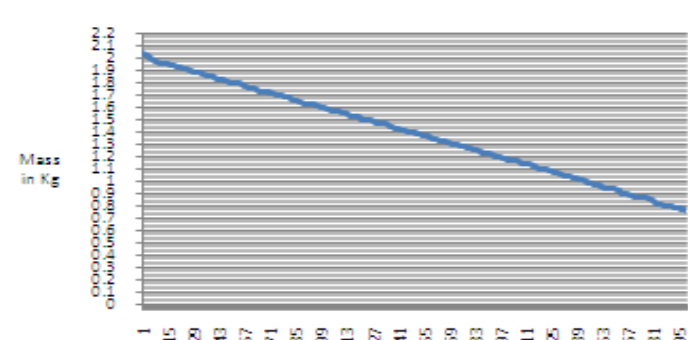

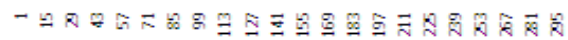
No. of iterations from PC Optimization

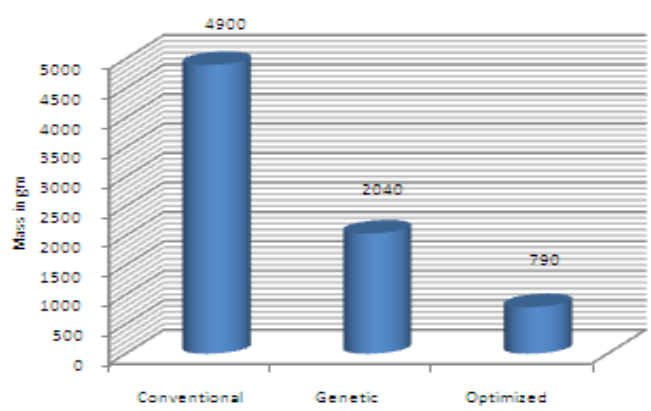



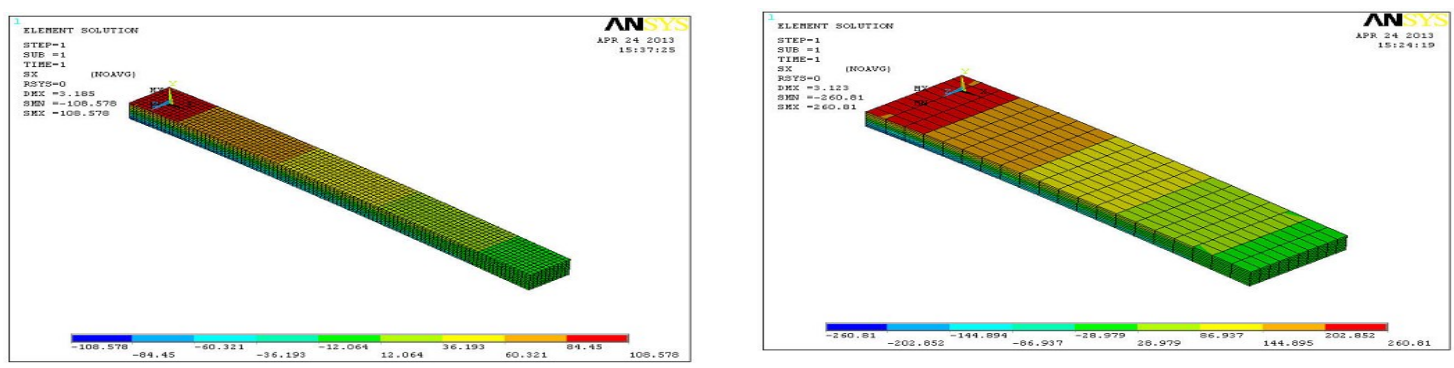

Fig1. Conventional steel cantilever beam for pre \& post optimization

\section{Design For Optimum Composite Cantilever Beam}

Compared to conventional materials, the application of composite materials can significantly improve the performance of various types of structures. A main advantage of composites is their high stiffness-mass and, composite materials are becoming increasingly used in structural applications. From aerospace to automotive, from naval to construction industries, there are attempts to replace classical materials (steel, concrete) by composite materials. The significant increase in the use of composite structures calls for accurate and efficient methods capable of modelling and optimizing under different set of conditions. In the last years some works have been developed relating to the analysis of composite beams (Woolley 1989; She et al. 1991; Bhaskar and Librescu 1995; Davalos and Qiao 1999).

Table 4: Material Properties carbon fiber reinforced epoxy resin [1]

\begin{tabular}{|l|c|c|c|}
\hline Property & Notation & Unit & Value \\
\hline Modulus of Elasticity & Exx & $\mathrm{GPa}$ & 126 \\
\hline Modulus of Elasticity & Eyy = Ezz & $\mathrm{GPa}$ & 11 \\
\hline Modulus of Rigidity & $\mathrm{Gxy}$ & $\mathrm{GPa}$ & 7 \\
\hline Modulus of Rigidity & $\mathrm{Gxz}$ & $\mathrm{GPa}$ & 5.5 \\
\hline Modulus of Rigidity & $\mathrm{Gyz}$ & $\mathrm{GPa}$ & 2.9 \\
\hline Poisson's ratio & $\mathrm{Nxy}$ & ----- & 0.3 \\
\hline Poisson's ratio & $\mathrm{Nxz}$ & ----- & 0.02 \\
\hline Poisson's ratio & $\mathrm{Nyz}$ & ----- & 0.02 \\
\hline Mass density & $\rho$ & $\mathrm{Kg} / \mathrm{m} 3$ & 1800 \\
\hline
\end{tabular}

\subsubsection{Modeling and Meshing:}

\section{Finite Element Modelling Of Composite Cantilever Beam}

Composite cantilever beam is modeled in finite element procedure from the dimensions obtained from optimization of the conventional steel cantilever beam for the initial analysis. The meshing of the modeled composite cantilever beam is made with the help of Linear layered structural shell element with six degrees of freedom per node, translations in the nodal $\mathrm{x}, \mathrm{y}$, and $\mathrm{z}$ directions and rotations about the nodal $\mathrm{x}, \mathrm{y}$, and $\mathrm{z}$-axes 3D. This element is represented in ANSYS as SHELL 99. The element divisions with element size $10 \mathrm{~mm}$ is take as longitudinally.

$\mathrm{x}_{\mathrm{IJ}}=$ Element $\mathrm{x}$-axis if ESYS is not supplied.

$\mathrm{x}=$ Element $\mathrm{x}$-axis if ESYS is supplied.

$\mathrm{LN}=$ Layer Number of Layers

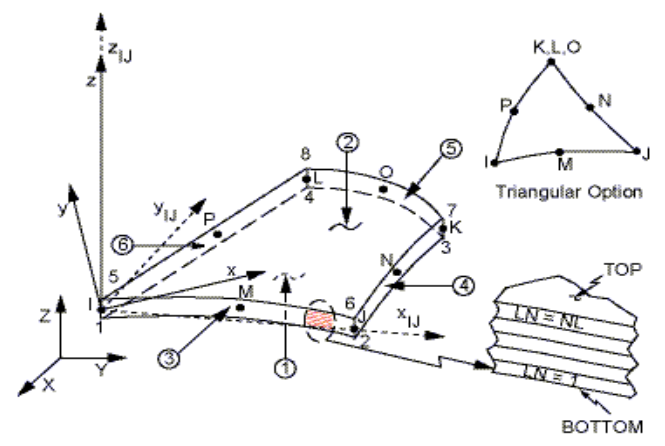




\subsubsection{Applied Boundary Conditions:}

This beam is fixed at one end keeping free at other for application of transverse load of magnitude $1000 \mathrm{~N}$ on the nodes of equally shared.

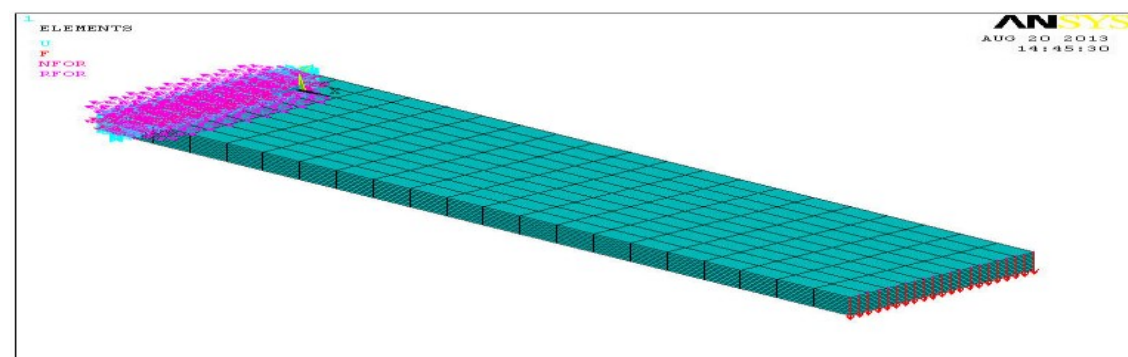

Fig2. Composite cantilever beam with applied boundary and initial conditions
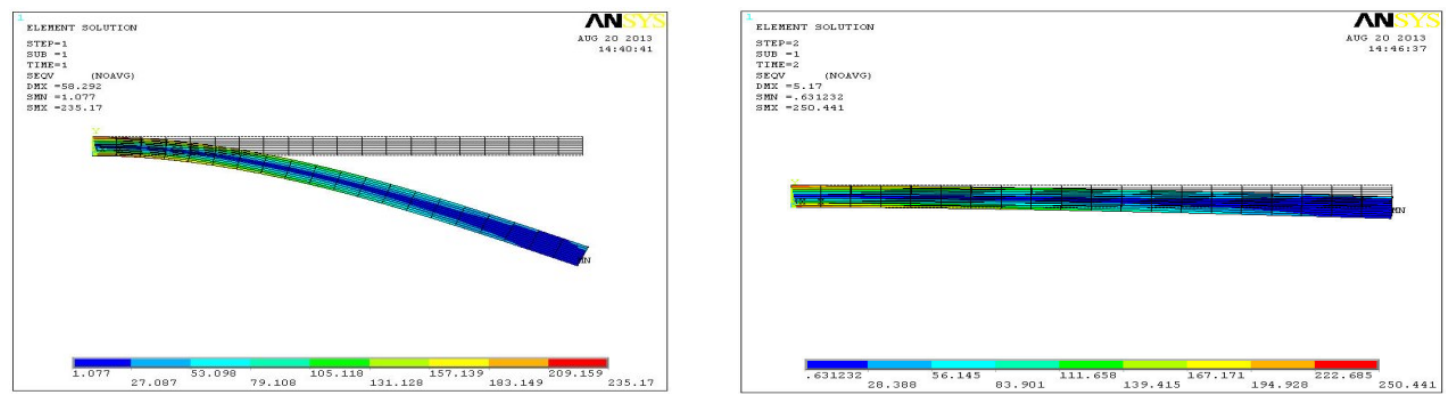

Fig 3. Composite cantilever beam strengthened with fiber orientation and stacking sequence
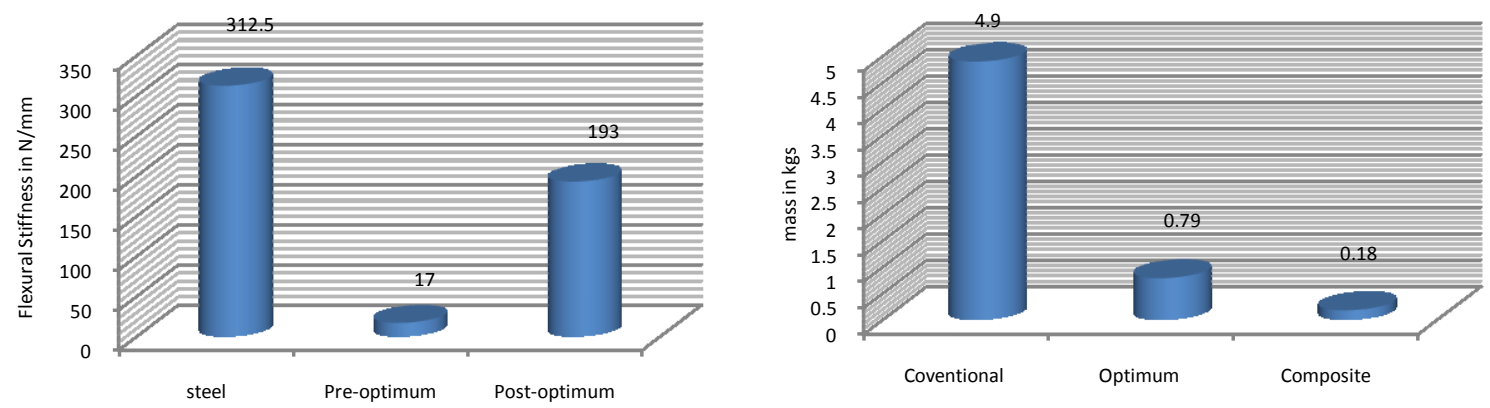

Table 5. Optimization from Steel to Pre-Tailored Composite cantilever beam

\begin{tabular}{|l|c|c|c|c|c|}
\hline \multicolumn{1}{|c|}{ Specification } & Conventional & $\begin{array}{c}\text { Conventional } \\
\text { Optimized }\end{array}$ & $\begin{array}{c}\text { Composite* } \\
\text { Pre Optimum }\end{array}$ & $\begin{array}{c}\text { Composite* } \\
\text { Post Optimum }\end{array}$ & Units \\
\hline Weight & 4.9 & 0.79 & 0.18 & 0.18 & $\mathrm{Kg}$ \\
\hline Stiffness & 312.5 & 312.5 & 17.152 & 193.42 & $\mathrm{~N} / \mathrm{mm}$ \\
\hline Bending Stress & 108 & 260 & 235 & 250 & $\mathrm{MPa}$ \\
\hline Deflection & 3.2 & 3.2 & 58.3 & 5.17 & $\mathrm{~mm}$ \\
\hline Length & 500 & 200 & 200 & 200 & $\mathrm{~mm}$ \\
\hline Breath & 50 & 50 & 50 & 50 & $\mathrm{~mm}$ \\
\hline Thickness & 10 & 10 & 10 & 10 & $\mathrm{~mm}$ \\
\hline
\end{tabular}

*Above values are pre-tailored optimum levels

\section{Tailoring And Optimizing The Composite Beam:}

Fiber reinforced composite materials have gained a widespread popularity over conventional materials in fields such as aerospace, construction, consumer products, transportation and sporting goods. For structural applications where high strength-to-weight and stiffness-to-weight ratios are required the fiber-reinforced composite materials are ideal. By altering lay-up and fiber orientations composite material can be tailored to meet the particular requirements of stiffness and strength. The ability to manufacture a composite material as per its job is one of the most significant advantages of composite material over an ordinary material. Due to the high strength to low weight ratio, resistance in fatigue and low damping factor, composite materials have wide range 
of applications in car and aircraft industries. Research in the design of mechanical, aerospace and civil structure and development of composite materials has grown tremendously in few decades.

"Tailoring is a process of removing unwanted material by topology optimization for strengthening and by reducing the weight of the structure". Tailored structure is further strengthened by optimizing the fiber orientation and stacking sequence in the structure. This satisfies the requirements as high -strength to weight ratio which is very much essential in recent years.

\section{Tailoring And Optimization Algorithm:}

1. Development of objective function.

2. Collection of design constraints.

3. Identification of design variables.

4. Modeling with the optimized topology using simulators.

5. Applying require boundary conditions on the model.

6. Applying require loading conditions on the model.

7. Solving the member using Simulation software's.

8. Analyzing the results for design requirements.

9. Search for weaker sections through analyzing results.

10. Strengthening the weaker sections by tailoring iterations.

11. Strengthening the weaker sections by optimization iterations

12. Strengthening can be done without violating constraints.

13. Journey towards optimal solution in objective function.

\section{Tailoring And Optimizing The Thickness Of The Composite Beam}

13.1. Reduction in cross-section with thickness over the length of the beam

Composite cantilever beam is modeled in finite element procedure with variation in thickness keeping length and width constant for different cross-sections, (CS) to maximize the stiffness and minimizing the weight. The meshing of the modeled composite cantilever beam is made with the help of Linear layered structural shell element with six degrees of freedom per node, translations in the nodal $\mathrm{x}, \mathrm{y}$, and $\mathrm{z}$ directions and rotations about the nodal $\mathrm{x}, \mathrm{y}$, and $\mathrm{z}$-axes 3D.

On a composite cantilever beam CS is framed by reducing the thickness from $2 \mathrm{CS}$ to $40 \mathrm{CS}$. Thus, if $\mathrm{t}=$ $10 \mathrm{~mm}$ is the initial thickness value, then for all cases $[\mathrm{t}-0.25(\mathrm{n}-1)] \mathrm{mm}$ in multiples of $\mathrm{n}$ lengths.
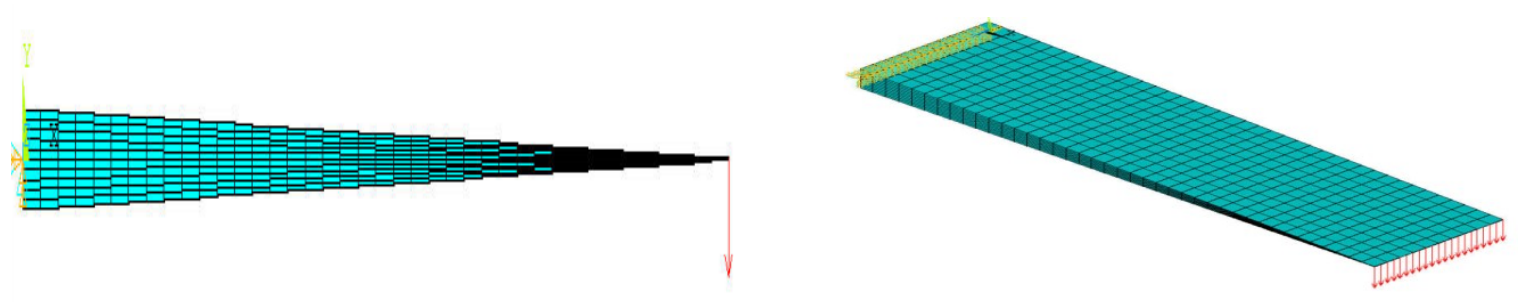

Fig4. 40CS Tailored Composite Cantilever Beam
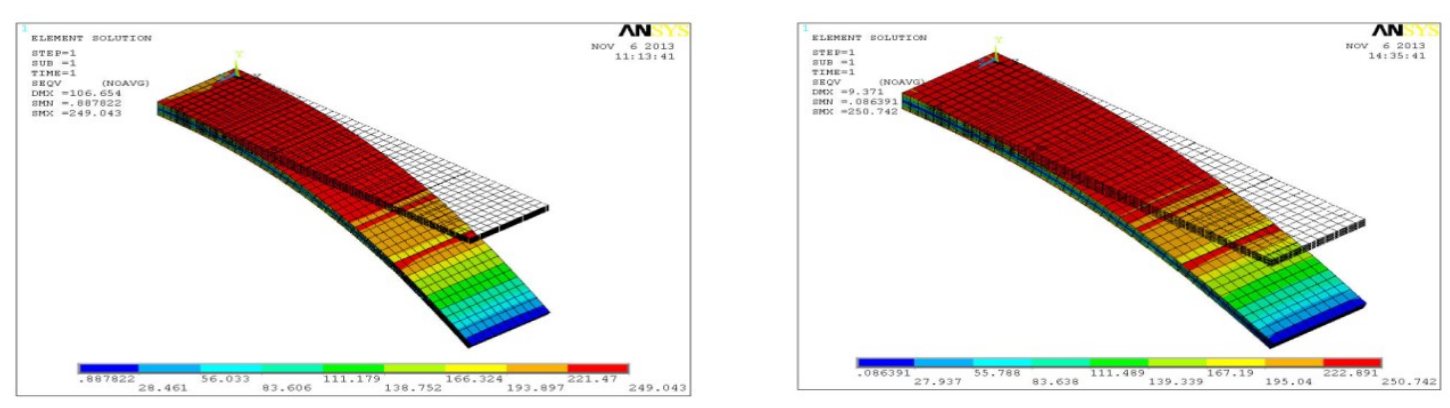

Fig5. 24 CS Strengthened Composite Beam before \& after optimization 
Tailoring of composite cantilever beam for maximum stiffness and minimum weight

Table 6: Reduction in cross-sections with thickness over the length of the beam

\begin{tabular}{|c|c|c|c|c|c|c|c|}
\hline \multirow{2}{*}{$\begin{array}{c}\text { THICKNESS } \\
\text { CROSS- } \\
\text { SECTIONS }\end{array}$} & \multicolumn{2}{|c|}{$\begin{array}{c}\text { DEFLECTION } \\
\text { (FREE END) } \\
\text { mm }\end{array}$} & \multicolumn{2}{|c|}{$\begin{array}{c}\text { FLEXURAL STIFFNESS } \\
\qquad \mathrm{N} / \mathrm{mm} \\
\end{array}$} & \multicolumn{2}{|c|}{$\begin{array}{c}\text { VONMISSES STRESS } \\
\mathbf{N} / \mathbf{m m}^{2}\end{array}$} & \multirow[t]{2}{*}{$\begin{array}{c}\text { MASS } \\
(\mathrm{gm})\end{array}$} \\
\hline & $\begin{array}{c}\text { Pre } \\
\text { optimum }\end{array}$ & $\begin{array}{c}\text { Post } \\
\text { optimum }\end{array}$ & $\begin{array}{c}\text { Pre } \\
\text { optimum }\end{array}$ & $\begin{array}{c}\text { Post } \\
\text { optimum }\end{array}$ & $\begin{array}{c}\text { Pre } \\
\text { optimum }\end{array}$ & $\begin{array}{c}\text { Post } \\
\text { optimum }\end{array}$ & \\
\hline $1 \mathrm{CS}$ & 58 & 5.17 & 17.24 & 193.42 & 239.12 & 243.64 & 180 \\
\hline $2 \mathrm{CS}$ & 58 & 5.217 & 17.24 & 191.68 & 239.12 & 243.65 & 177.8 \\
\hline $4 \mathrm{CS}$ & 61 & 5.402 & 16.39 & 185.11 & 239.12 & 243.7 & 173.3 \\
\hline $6 \mathrm{CS}$ & 55 & 5.6335 & 18.18 & 177.50 & 239.11 & 243.94 & 168.7 \\
\hline $8 \mathrm{CS}$ & 66 & 5.865 & 15.15 & 170.50 & 239.10 & 244.11 & 164.3 \\
\hline $10 \mathrm{CS}$ & 69 & 6.151 & 14.49 & 162.57 & 238.66 & 244.22 & 159.8 \\
\hline $12 \mathrm{CS}$ & 72 & 6.437 & 13.88 & 155.35 & 238.22 & 244.47 & 155.2 \\
\hline $14 \mathrm{CS}$ & 76 & 6.7935 & 13.15 & 147.19 & 238.23 & 244.67 & 150.7 \\
\hline $16 \mathrm{CS}$ & 80 & 7.15 & 12.50 & 139.86 & 238.24 & 244.86 & 146.3 \\
\hline $18 \mathrm{CS}$ & 85.5 & 7.609 & 11.69 & 131.42 & 238.61 & 245.07 & 141.7 \\
\hline $20 \mathrm{CS}$ & 91 & 8.068 & 10.98 & 123.94 & 238.99 & 245.28 & 137.3 \\
\hline $22 \mathrm{CS}$ & 98 & 8.7195 & 10.20 & 114.68 & 244.02 & 248.01 & 132.7 \\
\hline $24 \mathrm{CS}$ & 105 & 9.371 & 9.52 & 106.71 & 249.04 & 250.74 & 128.2 \\
\hline $26 \mathrm{CS}$ & 115 & 10.219 & 8.69 & 97.85 & 266.61 & 268.60 & 123.7 \\
\hline $28 \mathrm{CS}$ & 125 & 11.067 & 8.00 & 90.35 & 284.18 & 286.45 & 119.3 \\
\hline $30 \mathrm{CS}$ & 141 & 12.48 & 7.09 & 80.12 & 327.98 & 333.90 & 114.6 \\
\hline $32 \mathrm{CS}$ & 157 & 13.893 & 6.36 & 71.97 & 371.78 & 381.34 & 111.9 \\
\hline $34 \mathrm{CS}$ & 188 & 16.732 & 5.31 & 59.76 & 514.50 & 553.51 & 105.7 \\
\hline $36 \mathrm{CS}$ & 219 & 19.571 & 4.56 & 51.09 & 657.21 & 725.68 & 101.1 \\
\hline $38 \mathrm{CS}$ & 381.5 & 37.0035 & 2.62 & 27.02 & 5357.10 & 7551.34 & 96.7 \\
\hline $40 \mathrm{CS}$ & 544 & 54.436 & 1.83 & 18.37 & 10057 & 14377 & 92.3 \\
\hline
\end{tabular}

Pre Optimum $=[0 / 0 / 0 / 0 / 0 / 0 / 0 / 0 / 0 / 0]$

Post Optimum $=[90 / 0 /-45 / 90 / 45 /-45 / 90 / 45 / 0 / 90]$
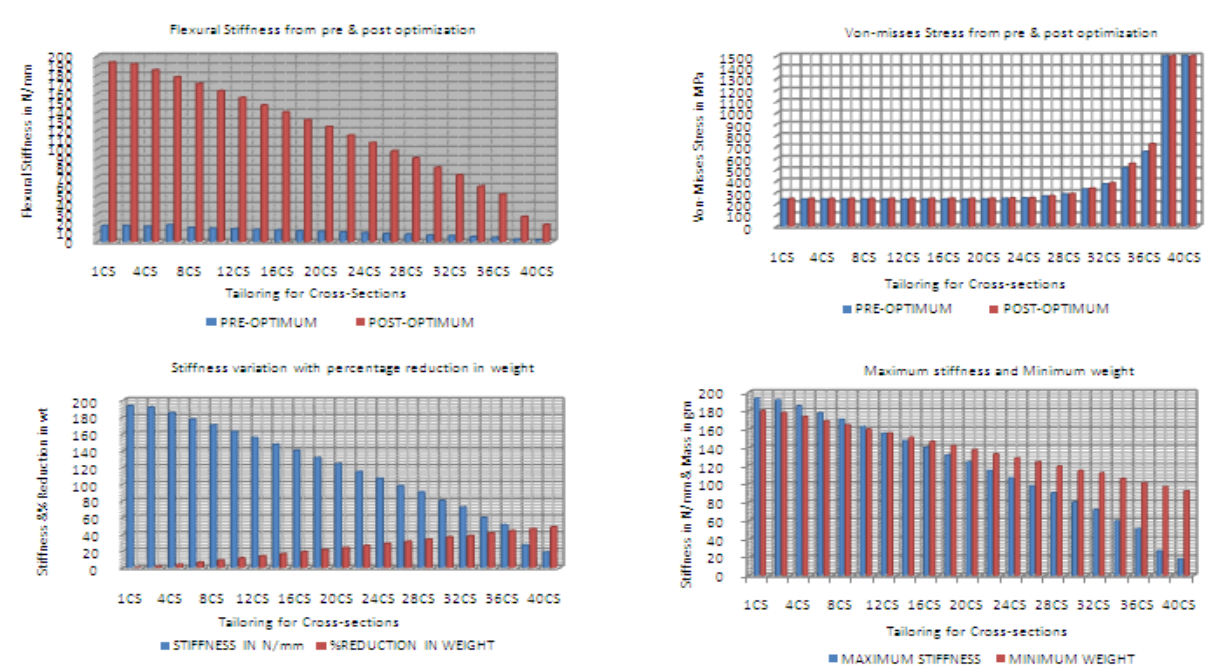

\subsection{Reduction in cross-section with thickness and width over the length of the beam}

Composite cantilever beam is modeled in finite element procedure with variation in thickness and width keeping length constant for different cross-sections (CS) to maximize the stiffness and minimizing the weight. The meshing of the modeled composite cantilever beam is made with the help of Linear layered structural shell element with six degrees of freedom per node, translations in the nodal $\mathrm{x}, \mathrm{y}$, and $\mathrm{z}$ directions and rotations about the nodal $\mathrm{x}, \mathrm{y}$, and z-axes 3D.

On a composite cantilever beam, CS is framed by reducing the thickness from 2CS to 40CS and width from 2CS to 16CS. Thus, if $\mathrm{t}=10 \mathrm{~mm}$ and $\mathrm{w}=50 \mathrm{~mm}$ is the initial thickness and width values respectively, then for all cases $[\mathrm{t}-0.25(\mathrm{n}-1)] \mathrm{mm} \&[\mathrm{w}-1.25(\mathrm{n}-1)] \mathrm{mm}$ in multiples of $\mathrm{n}$ lengths. 
Tailoring of composite cantilever beam for maximum stiffness and minimum weight
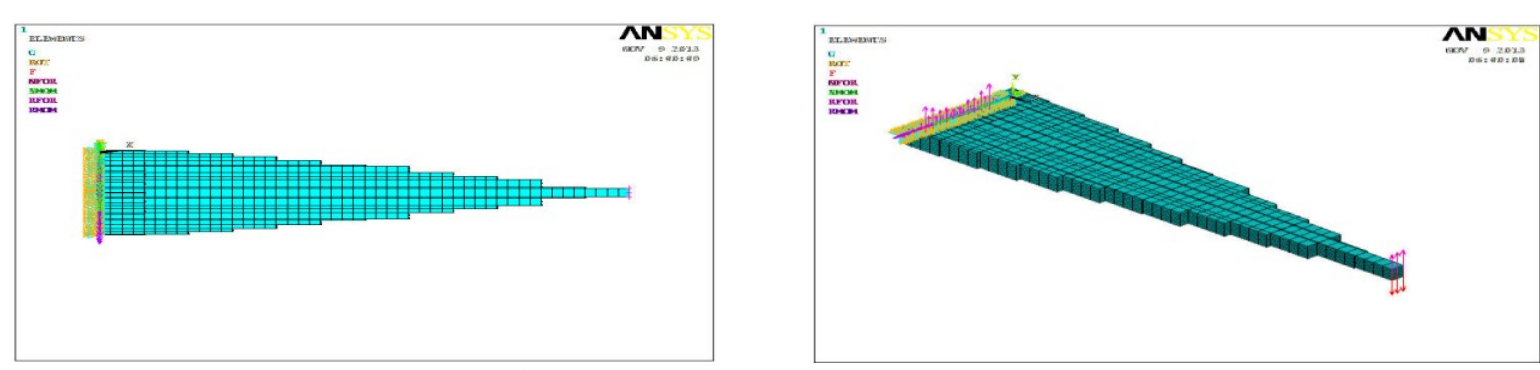

Fig6. 12CS Tailored Composite Cantilever Beam
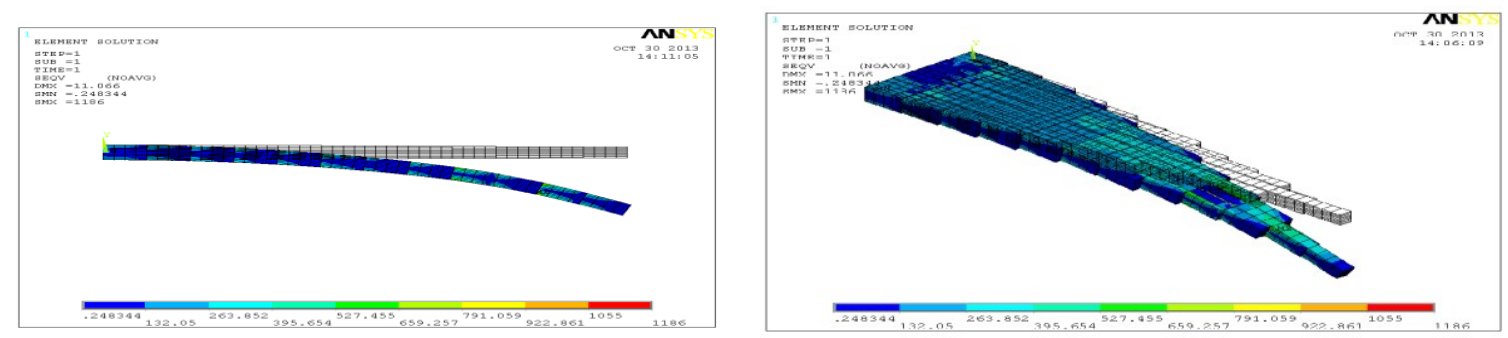

Fig7. 12CS Strengthened Composite Beam before \& after optimization

Table 7: Reduction in Cross-Sections with Width \& Thickness over the Length of the Beam

\begin{tabular}{|c|c|c|c|c|c|c|c|}
\hline \multirow{2}{*}{$\begin{array}{c}\text { WIDTH \& } \\
\text { THICKNESS } \\
\text { CROSS- } \\
\text { SECTIONS }\end{array}$} & \multicolumn{2}{|c|}{$\begin{array}{c}\text { DEFLECTION } \\
\text { (FREE END) } \\
\text { mm } \\
\end{array}$} & \multicolumn{2}{|c|}{$\begin{array}{c}\text { FLEXURAL STIFFNESS } \\
\mathrm{N} / \mathrm{mm} \\
\end{array}$} & \multicolumn{2}{|c|}{$\begin{array}{c}\text { VONMISSES STRESS } \\
\text { N/mm } \\
\end{array}$} & \multirow{2}{*}{$\begin{array}{c}\text { MASS } \\
\text { (gm) }\end{array}$} \\
\hline & $\begin{array}{c}\text { Pre } \\
\text { optimum }\end{array}$ & $\begin{array}{c}\text { Post } \\
\text { optimum }\end{array}$ & $\begin{array}{c}\text { Pre } \\
\text { optimum }\end{array}$ & $\begin{array}{c}\text { Post } \\
\text { optimum }\end{array}$ & $\begin{array}{c}\text { Pre } \\
\text { optimum }\end{array}$ & $\begin{array}{c}\text { Post } \\
\text { optimum }\end{array}$ & \\
\hline $1 \mathrm{CS}$ & 58 & 5.17 & 17.24 & 193.42 & 244.3 & 251.8 & 180 \\
\hline $2 \mathrm{CS}$ & 12.693 & 8.107 & 78.78 & 123.35 & 268.18 & 316.71 & 175.55 \\
\hline $4 \mathrm{CS}$ & 5.54 & 6.876 & 180.50 & 145.43 & 279.73 & 340.37 & 166.89 \\
\hline $6 \mathrm{CS}$ & 6.226 & 7.716 & 160.61 & 129.60 & 299.12 & 365.22 & 158.51 \\
\hline $8 \mathrm{CS}$ & 6.912 & 8.556 & 144.67 & 116.87 & 318.51 & 390.07 & 150.46 \\
\hline $10 \mathrm{CS}$ & 8.967 & 10.7165 & 111.52 & 93.31 & 752.25 & 877.53 & 142.70 \\
\hline $12 \mathrm{CS}$ & 11.022 & 12.877 & 90.72 & 77.65 & 1186 & 1365 & 135.18 \\
\hline $14 \mathrm{CS}$ & 10.282 & 12.202 & 97.25 & 81.95 & 1106.5 & 1322.5 & 128.03 \\
\hline $16 \mathrm{CS}$ & 9.542 & 11.527 & 104.79 & 86.75 & 1027 & 1280 & 121.21 \\
\hline
\end{tabular}

Pre Optimum $=[0 / 0 / 0 / 0 / 0 / 0 / 0 / 0 / 0 / 0]$

Post Optimum $=[90 / 0 /-45 / 90 / 45 /-45 / 90 / 45 / 0 / 90]$
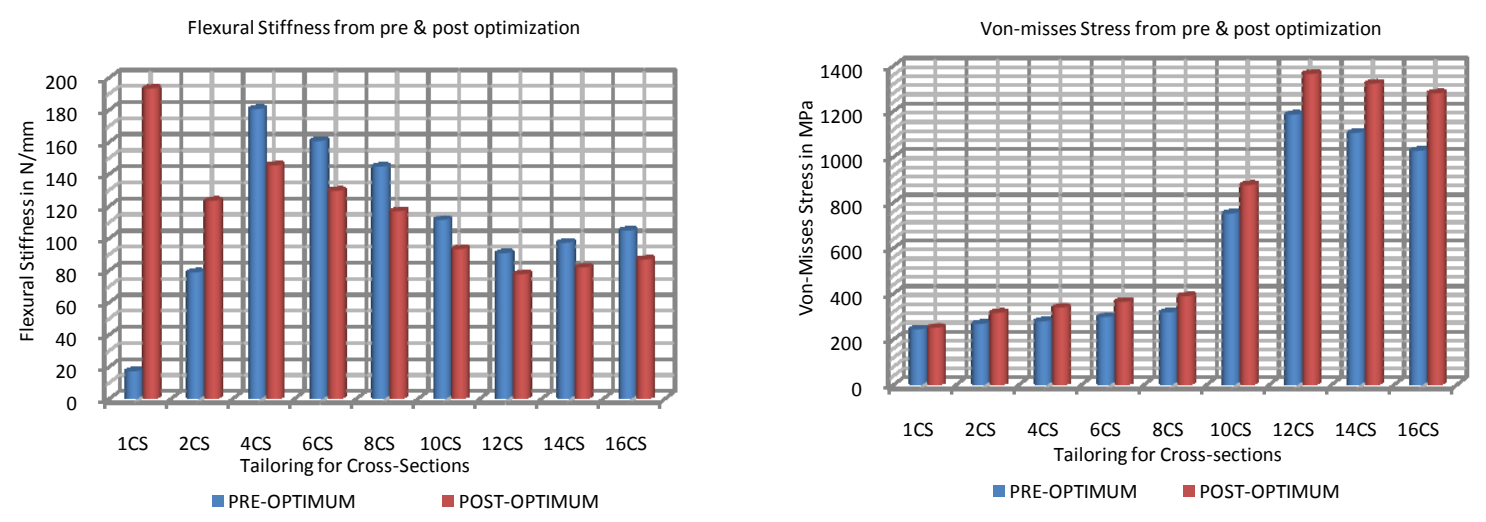

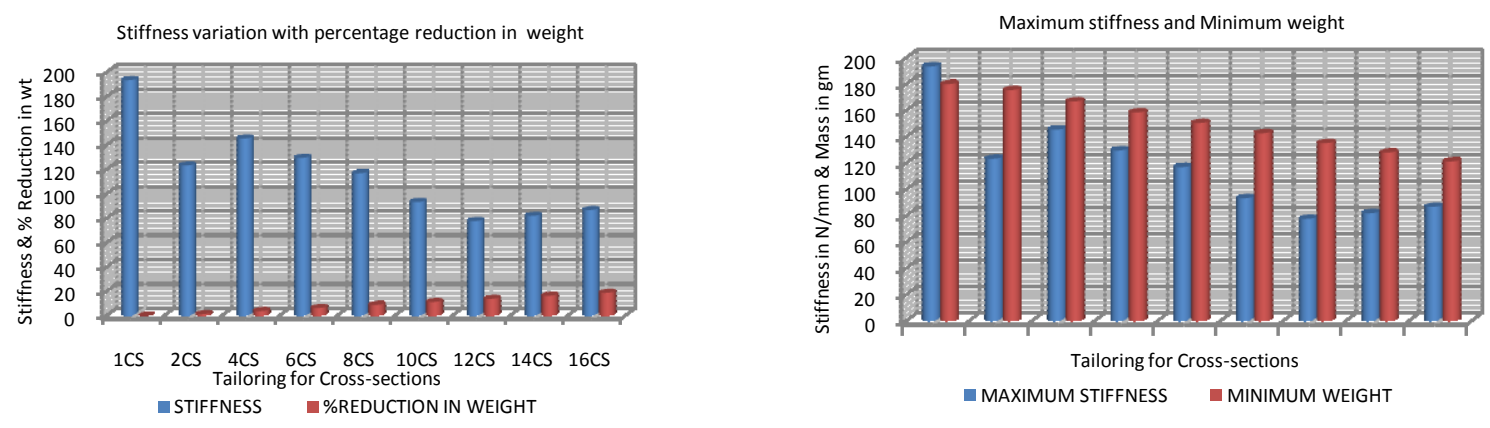

\section{CONCLUSIONS}

- Tailoring composite structures with proper intelligence and optimizing fiber orientation and stacking sequence tend to strengthen the structure and minimum weight.

- Tailoring in thickness is under acceptable limits up to $28 \mathrm{CS}$ for cross-sections over the length, shows strengthened beam and minimum weight.

- Tailoring in thickness and width is under acceptable limits up to $8 \mathrm{CS}$ for cross-sections over the length, shows strengthened beam and minimum weight.

\begin{tabular}{|c|c|c|c|c|}
\hline Conventional / Composite & $\begin{array}{l}\text { Flexural } \\
\text { Stiffness } \\
(\mathbf{N} / \mathbf{m m})\end{array}$ & $\begin{array}{l}\text { Weight } \\
\text { (grams) }\end{array}$ & $\begin{array}{l}\text { Percentage } \\
\text { Reduction }\end{array}$ & $\begin{array}{c}\text { Von-misses Stress } \\
\text { levels } \\
\text { MPa } \\
\end{array}$ \\
\hline Conventional Steel Beam (CSB) & 312.5 & 4900 & 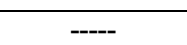 & 108 \\
\hline Optimized Steel Beam (OSB) & 312.5 & 790 & $(84 \%)$ & 260 \\
\hline \multicolumn{5}{|l|}{ Tailoring Thickness } \\
\hline $1 \mathrm{CS}$ & 193 & 180 & $\begin{array}{l}96 \% \text { with CSB } \\
77 \% \text { with OSB }\end{array}$ & 243 \\
\hline $28 \mathrm{CS}$ & 90 & 120 & $\begin{array}{l}98 \% \text { with CSB } \\
85 \% \text { with OSB } \\
33 \% \text { with } 1 \text { CS }\end{array}$ & 286 \\
\hline \multicolumn{5}{|l|}{ Tailoring Thickness \& Width } \\
\hline $1 \mathrm{CS}$ & 193 & 180 & $\begin{array}{l}96 \% \text { with CSB } \\
77 \% \text { with OSB }\end{array}$ & 243 \\
\hline $8 \mathrm{CS}$ & 144 & 150 & $\begin{array}{l}97 \% \text { with CSB } \\
81 \% \text { with OSB } \\
16 \% \text { with } 1 \text { CS }\end{array}$ & 318 \\
\hline
\end{tabular}

- Tailoring in thickness over the length is more acceptable when comparing to tailoring for thickness and width, based on maximizing stiffness and minimum weight.

- Depending up on the requirement of flexural stiffness, tailoring cross-sections is selected for minimizing the weight.

\section{REFERENCES:}

[1] José Pedro Blasques · Mathias Stolpe (2011) Maximum stiffness an minimum weight optimization of laminated composite beams using continuous fiber angles International Journal of Structural Multidisciplinary Optimization (2011) 43:573-588

[2] Behrooz Farshi, Saeed Herasati Optimum weight design of fiber composite plates in flexure based on a two level strategy Composite Structures 73(2006)495-504

[3] Peyman Khosravi - Ramin Sedaghati Design of laminated composite for optimum fiber direction and layer thickness ,using optimality criteria Struct Mutlidisc Optim (2008) 36:159-167

[4] Soren N.Sorensen .Erik Lund Topology and Thickness optimization of laminated composites including manufacturing constraints Struct Multidisc Optim

[5] Qi Xia . Michael Yu Wang .Tielin Shi A method for shape and topology optimization of truss-like structure Struct Mutlidisc Optim (2013) 47:687-697

[6] Dr.p.m.Pwar K.M.Markad Kundan Mishra Validation of thin-walled composite box beams using FEM ISSN:2278-1684 Volume 1, (July-August2012), PP 45-49

[7] Thimmegowda RANGASWAMY, Sabapathy VIJAYARANGAN Optimal Sizing and Stacking Sequence of Composite Drive Shafts ISSN 1392-1320 MATERIALS SCIENCE (MEDZIAGOTYRA). Vol 11, No. 2. 2005.

[8] Akira Todorokio and Yuichiro Terada $\dagger$ Improved Fractal Branch and Bound Method for Stacking-Sequence Optimizations of Laminates AIAA JOURNAL Vol. 42, No. 1, January 2004 